\title{
Perencanaan Strategis Sistem Informasi STMIK Cahaya Surya Kediri
}

\author{
Agustono Heriadi*1, M. Suyanto ${ }^{2}$, Sudarmawan ${ }^{3}$ \\ ${ }^{1}$ Teknik Informatika Universitas Nusantara PGRI Kediri \\ ${ }^{2,3}$ Magister Teknik Informatika STMIK AMIKOM Yogyakarta \\ E-mail: *11ikki.heri@gmail.com, ${ }^{2}$ yanto@ amikom.ac.id, ${ }^{3}$ sudarmawan@ amikom.ac.id
}

\begin{abstract}
Abstrak
Meningkatnya jumlah perguruan tinggi mengakibatkan semakin tingginya persaingan. STMIK Cahaya Surya Kediri adalah sebuah institusi pendidikan tinggi yang memiliki satu program pendidikan S1 Sistem Informasi. Dalam industri usaha jasa, sistem informasi merupakan alat yang dapat membantu memenangkan persaingan. Perencanaan strategis sistem informasi menjadi salah satu kunci sebelum menerapkan sistem informasi dan teknologi informasi pada perusahaan. Perencanaan strategis yang tepat dapat mendukung rencana dan pengembangan bisnis perusahaan. STMIK Cahaya Surya Kediri belum memiliki perencanaan strategis sistem informasi. Bentuk perencanaan strategis sistem informasi yang akan dibahas dalam kajian ini menggunakan metodologi Ward and peppard dengan alat bantu metode analisis Value Chain untuk analisa lingkungan bisnis internal, Five Forces Model untuk analisa lingkungan bisnis eksternal, dan McFarlan Strategic Grid untuk analisa kondisi SI/TI internal saat ini. Hasil dari analisis ini mendefinisikan perencanaan strategis sistem informasi berupa strategi bisnis sistem informasi, strategi manajemen sistem informasi dan teknologi informasi, strategi sistem informasi, gap analisis sistem informasi, dan rencana implementasi.
\end{abstract}

Kata kunci - Perencanaan strategis sistem informasi, value chain, five forces model, McFarlan strategic grid

\section{Abstract}

The increasing the number of college resulting in the higher competition. STMIK Cahaya Surya Kediri is an institution of higher education that have an educational program S1 Information System. In the business services industry, information system is a tool that can help win the competition. Strategic planning of information systems to be one of the key before implementing information systems and information technology in the enterprise. Proper strategic planning to support the company's plans and business development. STMIK Cahaya Surya Kediri not have a strategic planning information system. Form of strategic planning of information systems that will be discussed in this study using a methodology Ward and Peppard with aids Value Chain analysis method for internal business environment analysis, Five Forces Model for the analysis of the external business environment, and McFarlan Strategic Grid to analyze the condition of the IS/IT internal current. The results of this analysis defines the strategic planning of information systems in the form of business strategy information systems, information systems and information technology management strategy, information systems strategy, information systems gap analysis, and implementation plan.

Keywords - Strategic information system plan, value chain, five forces model, McFarlan strategic grid 


\section{PENDAHULUAN}

Persaingan bisnis yang semakin ketat sehingga menuntut setiap perusahaan yang ingin memenangkan persaingan harus selalu membenahi diri dan memiliki strategi yang tepat dalam menjalankan bisnisnya. Selain itu, perkembangan teknologi yang begitu cepatnya tidak dapat diabaikan, karena perusahaan yang dapat memanfaatkan teknologi dengan tepat akan memberikan nilai tambah bagi perusahaan pada masing-masing sisi operasionalnya.

Sekolah Tinggi Manajemen Informatika dan Ilmu Komputer Cahaya Surya Kediri (STMIK CSK) yang berdiri sejak 28 Januari 2002 di Kediri merupakan institusi pendidikan tinggi yang selalu berkembang dalam meningkatkan mutu pendidikan dan pelayanan kepada mahasiswa yang tercermin dari salah satu misinya yaitu menyelenggarakan proses pembelajaran yang adaptif terhadap perubahan dan suasana akademik yang kondusi serta dukungan fasilitas yang memadai. Pada mulanya, STMIK CSK hanya memiliki satu kampus saja di Jl. Kyai Mojo no. 23, tetapi dengan berdirinya kampus dua di Jl. Perintis Kemerdekaan no. 36 A sejak awal tahun 2012 yang memiliki sarana ruang belajar, penambahan fasilitas olahraga, tempat parkir yang lebih nyaman, maka daya tarik dan daya saing dari STMIK CSK akan bertambah.

STMIK CSK saat ini, sesuai data yang tercatat pada akhir semester genap tahun akademik 2012/2013 memiliki mahasiswa aktif sejumlah 85, dan mahasiswa yang sudah lulus sebanyak 24 . STMIK CSK memiliki dosen tetap sebanyak 8 dosen tetap dan 10 dosen tidak tetap. Dengan semakin bertambahnya jumlah mahasiswa yang aktif, yang terlihat dari data jumlah mahasiswa pada awal berdiri tahun 2002 yang berjumlah 8 orang, dan data mahasiswa saat ini yang aktif sejumlah 85 mahasiswa, maka layanan yang harus diberikan dan suasana akademik harus tetap kondusif dan terjaga. Oleh karena itu diperlukan sebuah perencanaan strategis sistem informasi yang tepat untuk mendukung layanan dan suasana akademik yang sudah ada.

Tujuan dari penelitian ini adalah membuat perencanaan strategis di bidang sistem informasi untuk STMIK Cahaya Surya Kediri khususnya program studi Sistem Informasi menggunakan metodologi Ward and Peppard dengan metode analisis Value Chain untuk memberikan keunggulan atau nilai tambah dari layanan yang tersedia, Five Forces Model untuk melihat analisa kompetitif di tingkat industri, dan McFarlan Strategic Grid untuk mengetahui dampak strategis dari sistem informasi.

Adapun batasan pada penelitian ini adalah studi kasus dilakukan pada perusahaan jasa yang berupa sebuah institusi pendidikan Sekolah Tinggi Manajemen Informatika dan Ilmu Komputer Cahaya Surya Kediri (STMIK CSK); hasil akhir dari penelitian ini berupa portfolio perencanaan strategis SI/TI; perencanaan strategis dibuat dan dikembangkan dari SI/TI yang ada pada saat penelitian dilakukan agar sesuai dengan arah perkembangan organisasi dan juga visi, misi dan tujuan dari institusi tempat penelitian; metodologi yang digunakan adalah metodologi dari Ward dan Peppard dengan alat bantu yang digunakan adalah metode analisis value chain untuk analisa lingkungan bisnis internal kampus, metode analisis Five Forces Model untuk analisa lingkungan bisnis eksternal kampus, dan metode analisis McFarlan Strategic Grid untuk analisa kondisi SI/TI internal saat ini.

Penelitian oleh Rahman Rosyidi dengan judul Perencanaan Sistem Informasi Strategis STMIK AMIKOM Purwokerto. Penelitian ini mencoba membuat perencanaan sistem informasi strategis menggunakan metode Ward and Peppard untuk STMIK AMIKOM Purwokerto. Metode analisis yang digunakan dalam penelitian ini adalah Five Forces Model, SWOT, Value Chain dan Five Forces Model [1].

Penelitian oleh Licantik dengan judul Perencanaan Strategis Teknologi Informasi di Lingkungan Pemerintah Daerah Kabupaten Gunung Mas Provinsi Kalimantan Tengah. Penelitian ini mencoba membuat perencanaan strategis teknologi informasi menggunakan metode Ward and Peppard untuk KPPT Pemerintah Daerah Kabupaten Gunung Mas Provinsi Kalimantan Tengah. Metode analisis yang digunakan dalam penelitian ini adalah Critical Success Factors, SWOT, Value Chain, PEST, dan Five Forces Model [2].

Menurut Robbins dan Coulter (1999), perencanaan adalah suatu proses yang melibatkan penentuan sasaran atau tujuan organisasi, menyusun strategi menyeluruh untuk mencapai sasaran 
yang ditetapkan dan mengembangkan hirarki rencana secara menyeluruh untuk mengintegrasikan dan mengkoordinasikan kegiatan [3].

Menurut Ward dan Peppard (Ward, 2002), strategi dapat didefinisikan sebagai suatu rangkaian tindakan-tindakan terpadu yang menjadi alat untuk meningkatkan keberhasilan dan kekuatan jangka panjang sebuah perusahaan dalam mencapai keunggulan bersaing [4].

Menurut O'Brien (2003), sistem informasi adalah kombinasi sumber daya yang terorganisir dari manusia, perangkat keras, piranti lunak, jaringan komputer dan data yang mengumpulkan, mengubah dan mendistribusikan informasi pada suatu organisasi [5].

Menurut Ward dan Peppard (2002), strategi SI adalah strategi yang mendefinisikan kebutuhan organisasi atau perusahaan terhadap informasi dan sistem yang mendukung keseluruhan strategi bisnis yang dimiliki organisasi tersebut [4]. Hal ini, dihubungkan dengan konteks bisnis dengan mempertimbangkan dampak persaingan dalam bisnis dan kebutuhan perusahaan terhadap teknologi informasi atau sistem informasi. Pada dasarnya, strategi SI mendefinisikan dan memprioritaskan investasi yang harus dilakukan perusahaan untuk mencapai portfolio aplikasi yang sesuai, mendefinisikan tujuan yang akan dicapai dan menentukan perubahan yang harus dilakukan untuk mencapai tujuan tersebut.

Rencana strategis SI yang akan dibuat ini dapat digunakan untuk membantu manajemen dalam menentukan sistem informasi yang diperlukan untuk dibuat dan juga sistem informasi yang perlu tetap ada ataupun dikembangkan.

Analisis value chain adalah kegiatan menganalisis kumpulan aktivitas yang dilakukan untuk merancang, memproduksi, memasarkan, mengantarkan, dan mendukung produk atau jasa [4]. Pendekatan value chain dibedakan menjadi dua tipe aktivitas bisnis, yaitu aktivitas utama (primary activities) dan aktivitas pendukung (support activities).

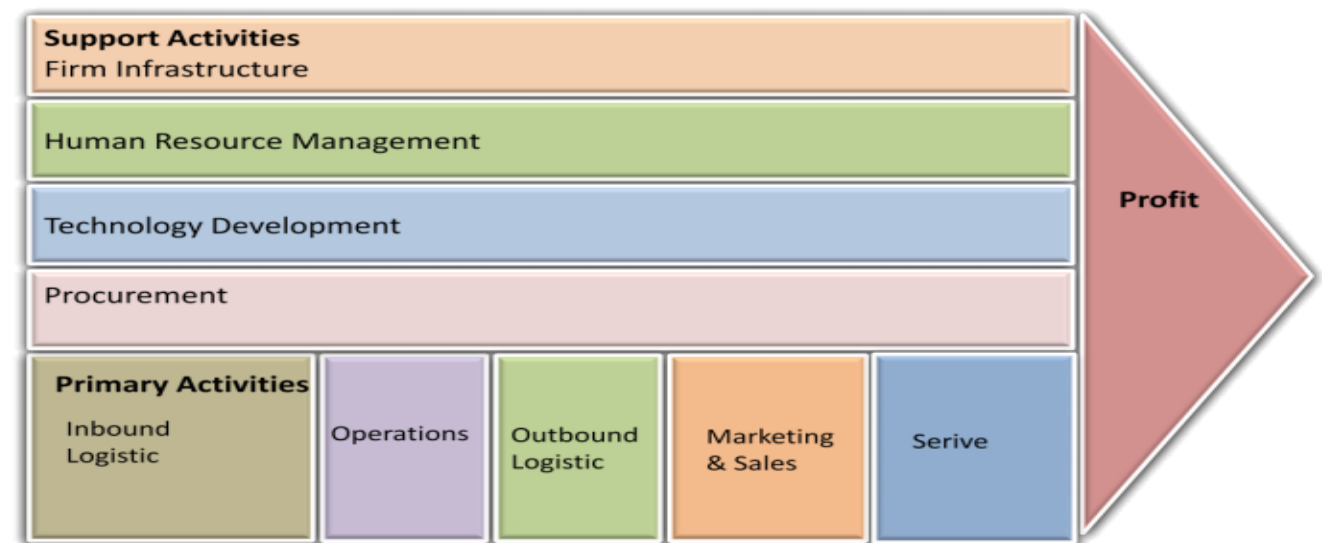

Gambar 1. Diagram Value Chain

Untuk menganalisa dan memahami faktor eksternal dari organisasi pada organisasi atau organisasi, yaitu ancaman serta peluangnya, maka dapat digunakan Porter Competitive Model [6]. Model ini digunakan untuk mengetahui dan mengevaluasi struktur lingkungan industri bisnis serta ancaman persaingan. Perlu diketahui bahwa model porter ini bukan khusus digunakan untuk membangun analisis SI dalam persaingan, tetapi digunakan untuk mengetahui posisi bersaing bisnis. 


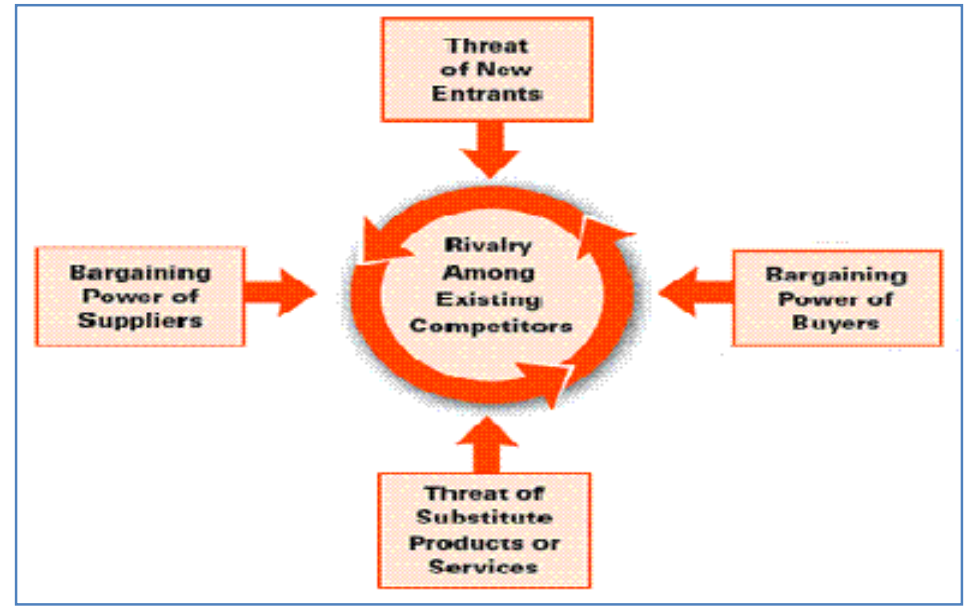

Gambar 2. Five Forces Model Porter [7]

McFarlan Strategic Grid digunakan untuk memetakan aplikasi sistem informasi berdasarkan kontribusinya terhadap perusahaan. Pemetaan dilakukan pada empat kuadran (strategic, high potential, key operation, and support). Dari hasil pemetaan tersebut didapatkan gambaran kontribusi sebuah aplikasi sistem informasi terhadap perusahaan dan pengembangan di masa mendatang.

\begin{tabular}{|c|c|}
\hline STRATEGIC & HIGH POTENTIAL \\
\hline $\begin{array}{c}\text { Applications that are critical to } \\
\text { sustaining future business strategy }\end{array}$ & $\begin{array}{c}\text { Applications that may be } \\
\text { important in achieving future } \\
\text { success }\end{array}$ \\
organization currently depends for & Applications that are valuable but \\
success & not critical to success \\
\hline KEY OPERATIONAL & SUPPORT
\end{tabular}

Gambar 3. McFarlan Strategic Grid [4]

\section{METODE PENELITIAN}

Pengumpulan data untuk penelitian ini dilakukan dengan melakukan wawancara kepada Ketua STMIK Cahaya Surya Kediri, dan Kepala BAA STMIK Cahaya Surya Kediri, serta melakukan observasi di lingkungan kampus STMIK Cahaya Surya Kediri, unit-unit administrasi, aplikasi sistem informasi yang digunakan, dan infrastruktur teknologi yang telah dimiliki oleh STMIK Cahaya Surya Kediri.

Pada penelitian ini, untuk membuat perencanaan strategis di bidang sistem informasi untuk STMIK Cahaya Surya Kediri akan digunakan beberapa macam metode analisis agar bisa diperoleh hasil analisa yang lengkap. Berikut ini gambar mengenai kerangka berpikir penulis yang akan dibuat. 
Citec Journal, Vol. 1, No. 1, November 2013 - Januari 2014

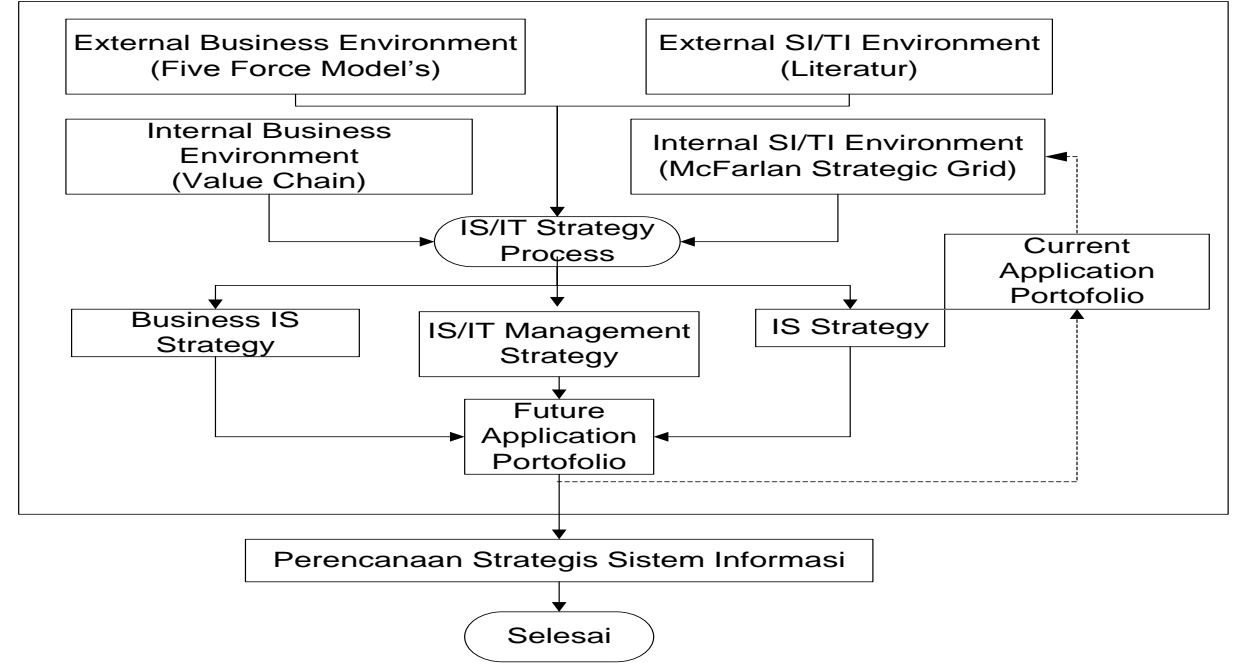

Gambar 4. Skema Alur Penelitian

Analisis lingkungan bisnis internal yang mencakup aspek-aspek bisnis saat ini, sasaran, sumber daya, proses, serta nilai-nilai budaya bisnis organisasi menggunakan metode analisis value chain. Analisis lingkungan bisnis eksternal, yang mencakup aspek-aspek bersaing perusahaan menggunakan metode analisis Five Forces Model. Analisis lingkungan SI/TI internal, yang mencakup kondisi SI/TI institusi dari perspektif bisnis saat ini, bagaimana kontribusi terhadap bisnis, ketrampilan sumber daya manusia, termasuk juga bagaimana portfolio dari SI/TI yang ada saat ini menggunakan McFarlan Strategic Grid. Analisis lingkungan SI/TI eksternal, yang mencakup tren teknologi dan peluang pemanfaatannya.

Dari hasil analisa tersebut, nantinya akan dihasilkan perencanaan strategis sistem informasi untuk STMIK Cahaya Surya Kediri berupa strategi bisnis SI, strategi manajemen SI/TI, dan strategi SI.

\section{HASIL DAN PEMBAHASAN}

Berikut hasil analisis value chain pada STMIK Cahaya Surya Kediri untuk pembagian aktifitas pada masing-masing unit:

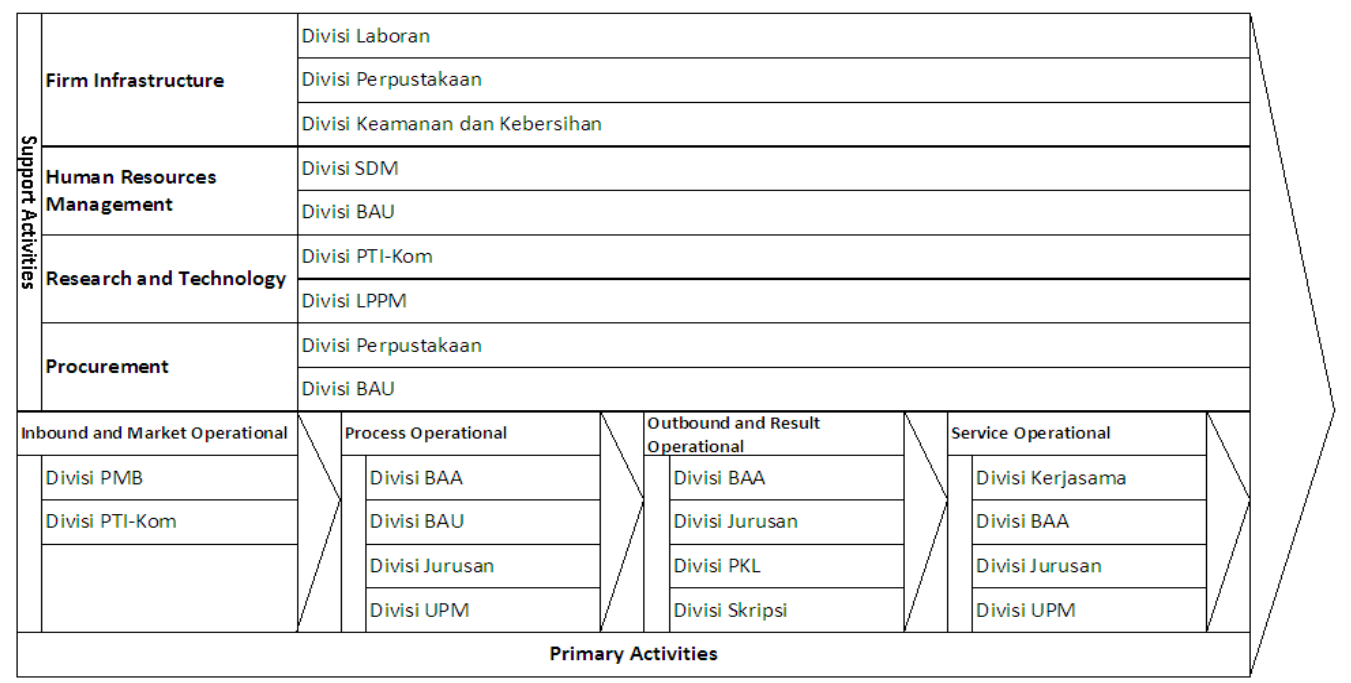

Gambar 5. Analisa Value Chain 
Metode analisis Five Forces Model digunakan untuk menentukan posisi STMIK Cahaya Surya Kediri terhadap lingkungan eksternal yang mempengaruhi jalannya proses bisnis pada STMIK Cahaya Surya Kediri. Berikut ini adalah hasil analisis Five Forces Model:

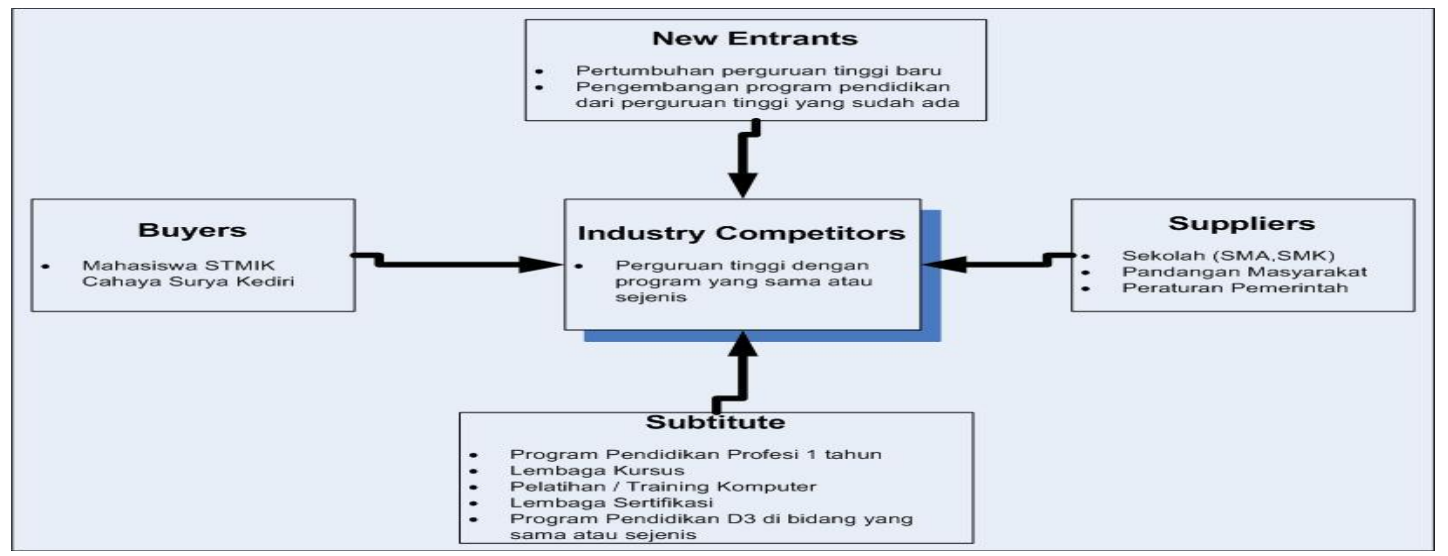

Gambar 6. Analisa Five Forces Model

Sistem Informasi yang ada saat ini dimiliki oleh STMIK Cahaya Surya Kediri umumnya dibuat dengan memesan sesuai kebutuhan spesifik dari aplikasi yang akan digunakan. Sistem informasi yang ada di STMIK Cahaya Surya Kediri dapat dilihat pada tabel di bawah ini:

Tabel 1. Daftar Sistem Informasi STMIK Cahaya Surya Kediri

\begin{tabular}{|c|c|c|}
\hline No. & $\begin{array}{l}\text { Nama Sistem } \\
\text { Informasi }\end{array}$ & Keterangan / Fitur \\
\hline \multirow[t]{4}{*}{1} & \multirow[t]{4}{*}{ SI Akademik } & Data Mata Kuliah (kurikulum) \\
\hline & & Data Nilai per Mahasiswa \\
\hline & & KHS \\
\hline & & Transkrip \\
\hline \multirow[t]{2}{*}{2} & \multirow[t]{2}{*}{ SI Penggajian } & Data Penghitungan Gaji Dosen dan Karyawan \\
\hline & & $\begin{array}{l}\text { Pencetakan Slip Gaji Pembayaran Dosen dan } \\
\text { Karyawan }\end{array}$ \\
\hline \multirow[t]{4}{*}{3} & \multirow[t]{4}{*}{ SI EPSBED } & Evaluasi Program Studi Berbasis Evaluasi Diri \\
\hline & & Evaluasi Data Dosen \\
\hline & & Evaluasi Data Mahasiswa \\
\hline & & Evaluasi Kurikulum Program Studi \\
\hline \multirow[t]{2}{*}{4} & \multirow[t]{2}{*}{ SI Perpustakaan } & Transaksi Peminjaman Buku \\
\hline & & Transaksi Pengembalian Buku \\
\hline \multirow[t]{2}{*}{5} & \multirow{2}{*}{$\begin{array}{l}\text { SI Presensi } \\
\text { Karyawan }\end{array}$} & Pencatatan Kehadiran Karyawan \\
\hline & & Penghitungan Data Kehadiran Karyawan \\
\hline \multirow[t]{2}{*}{6} & \multirow{2}{*}{$\begin{array}{l}\text { SI Jadwal } \\
\text { Perkuliahan }\end{array}$} & Pembuatan Rencana Pengajaran Mata Kuliah \\
\hline & & Pembuatan Rencana Pengajaran Dosen \\
\hline \multirow[t]{2}{*}{7} & \multirow[t]{2}{*}{ Website Kampus } & $\begin{array}{l}\text { Informasi tentang STMIK Cahaya Surya } \\
\text { Kediri }\end{array}$ \\
\hline & & Informasi tentang Event \\
\hline
\end{tabular}


Citec Journal, Vol. 1, No. 1, November 2013 - Januari 2014

Dari hasil analisis internal SI/TI, dapat dipetakan aplikasi yang ada saat ini di STMIK Cahaya Surya Kediri menggunakan McFarlan Strategic Grid berikut ini:

Tabel 2. Current Application Portfolio

\begin{tabular}{|l|l|}
\hline \multicolumn{1}{|c|}{ Strategic } & \multicolumn{1}{c|}{ High Potential } \\
\hline SI Akademik & \\
& \\
\hline SI Penggajian & Internet \\
SI EPSBED & Website Kampus \\
SI Perpustakaan & \\
SI Presensi & \\
Karyawan & \\
\hline \multicolumn{1}{|c|}{ Key Operational } & \multicolumn{1}{|c|}{ Support } \\
\hline
\end{tabular}

Perencanaan strategis sistem informasi disusun berdasarkan analisa internal dan eksternal lingkungan bisnis serta analisa internal dan eksternal lingkungan SI/TI dari kampus STMIK Cahaya Surya Kediri. Dari hasil analisa tersebut maka didapatkan perencanaan strategis sistem informasi ke depan sehingga membantu menentukan portfolio aplikasi SI dari STMIK Cahaya Surya Kediri yang harus dibangun. Penentuan strategi tersebut akan diawali oleh penentuan strategi bisnis sistem informasi, kemudian penentuan strategi manajemen SI/TI, dan strategi SI dari STMIK Cahaya Surya Kediri.

Penentuan strategi bisnis diawali dengan perumusan visi dan misi SI/TI yang selaras dengan visi, misi serta tujuan dari STMIK Cahaya Surya Kediri. Berdasarkan dokumen dan hasil penelitian pada STMIK Cahaya Surya Kediri, maka visi dan misi SI/TI STMIK Cahaya Surya Kediri dapat dirumuskan sebagai berikut:

\section{Visi}

- Menjadi fasilitator pendukung terwujudnya visi, misi, dan tujuan kampus dengan pemanfaatan sistem informasi dan teknologi informasi

Misi

- Mengembangkan produk SI/TI yang meningkatkan daya saing kampus.

- Menyediakan informasi yang bersifat operasional dan strategis untuk kebutuhan akademik kampus.

Strategi yang baik dalam pengelolaan SI/TI kampus sangat diperlukan agar pelaksanaan SI/TI berhasil dengan baik, sehingga proses bisnis kampus dapat berjalan lebih efektif dan efisien sehingga strategi bisnis kampus dapat terlaksana.

Strategi manajemen SI/TI diperoleh dari hasil analisis perencanaan strategis sistem informasi berupa kebijakan organisasi dalam menerapkan strategi SI/TI sesuai kondisi manajemen STMIK Cahaya Surya Kediri. Strategi manajemen SI/TI yang diterapkan meliputi restrukturisasi organisasi STMIK Cahaya Surya Kediri, pengembangan kompetensi SDM tentang SI/TI, dan pembuatan kebijakan SI/TI.

Pada struktur organisasi yang ada sudah terdapat divisi PTI-Kom (Pusat Teknologi Informasi - Komputer) yang dapat menangani hal yang berkaitan dengan SI/TI, akan tetapi untuk lebih memaksimalkan layanan SI/TI yang nantinya akan dikembangkan, akan lebih baik dengan adanya unit tersendiri yang nantinya tetap berhubungan dengan divisi PTI-Kom selaku penanggung jawab utama. Divisi yang ditambahkan diantaranya adalah Divisi Pemanfaatan SI/TI yang memiliki Unit Pengembangan Sistem Informasi dan unit Infrastruktur Teknologi Informasi. 
Strategi SI bertujuan untuk mengumpulkan dan mengidentifikasi kebutuhan-kebutuhan strategi bisnis organisasi untuk diterjemahkan dalam bentuk solusi SI yang dapat mendukung strategi bisnis.

Berdasarkan identifikasi kebutuhan SI STMIK Cahaya Surya Kediri hasil analisa value chain dari aktifitas utama dan pendukung, maka dapat disusun Future Application Portfolio menggunakan McFarlan’s Strategic Grid seperti tampak pada Tabel 3.

Tabel 3. Future Application Portfolio

\begin{tabular}{|l|l|}
\hline \multicolumn{1}{|c|}{ Strategic } & \multicolumn{1}{c|}{ High Potential } \\
\hline Website Kampus & SI Pendaftaran Mahasiswa Baru \\
SI Penjaminan Mutu & SI Manajemen Data Mahasiswa \\
SI Akademik & SI Manajemen Data Dosen \\
SI Alumni dan Tracer & SI Manajemen Data Karyawan \\
SI Kerjasama & SI Keuangan \\
& SI Lowongan Kerja \\
\hline SI Pengajian & Internet \\
SI EPSBED & Aplikasi Perkantoran \\
SI Penjadwalan Kuliah & SI Beasiswa \\
SI Perpustakaan & \\
SI Presensi Karyawan & \\
SI PKL dan Skripsi & \\
SI LPPM & \\
SI Inventaris & \\
\hline \multicolumn{1}{|c|}{ Key Operational } & \multicolumn{1}{|c|}{ Support } \\
\hline
\end{tabular}

GAP Analisis Sistem Informasi merupakan metode untuk membandingkan sistem informasi yang ada saat ini (current application) dengan kebutuhan sistem informasi yang merupakan hasil perencanaan strategis sistem informasi dari STMIK Cahaya Surya Kediri.

\begin{tabular}{|c|c|c|c|c|c|c|c|c|c|}
\hline & IS Need & SI Akademik & $\begin{array}{c}\text { SI } \\
\text { Penggajian } \\
\end{array}$ & SI EPSBED & $\begin{array}{c}\text { SI } \\
\text { Perpustaka } \\
\end{array}$ & $\begin{array}{l}\text { SI Presensi } \\
\text { Karyawan } \\
\end{array}$ & $\begin{array}{c}\text { SI Jadwal } \\
\text { Perkuliahan }\end{array}$ & $\begin{array}{l}\text { Website } \\
\text { Kampus }\end{array}$ & \\
\hline 1 & Aplikasi Perkantorat & & & & & & & & Baru \\
\hline 2 & SI Akademik & Kembangkan & & & & & & & \\
\hline 3 & SI Alumni & & & & & & & & Baru \\
\hline 4 & SI Beasiswa & & & & & & & & Baru \\
\hline 5 & SI EPSBED & & & Tetap & & & & & \\
\hline 6 & SI Inventaris & & & & & & & & Baru \\
\hline 7 & SI Kerjasama & & & & & & & & Baru \\
\hline s & SI Keuangan & & & & & & & & \begin{tabular}{|l|} 
Baru \\
\end{tabular} \\
\hline 9 & SI Loker & & & & & & & & Baru \\
\hline 10 & SI LPPM & & & & & & & & Baru \\
\hline 11 & SI Manajemen Data & & & & & & & & Baru \\
\hline 12 & SI Manajemen Data & & & & & & & & Baru \\
\hline 13 & SI Manajemen Data & & & & & & & & Banu \\
\hline 14 & SI Pendaftaran Mab; & & & & & & & & Baru \\
\hline 15 & SI Penggajian & & Tetap & & & & & & \\
\hline 16 & SI Penjadwalan Kuli; & & & & & & Kembangkan & & \\
\hline 17 & SI Penjaminan Mutu & & & & & & & & Baru \\
\hline 18 & SI Perpustakaan & & & & Tetap & & & & \\
\hline 19 & SI PKL \& Skripsi & & & & & & & & Baru \\
\hline 20 & SI Presensi & & & & & Tetap & & & \\
\hline 21 & Website Kampus & & & & & & & Kembangkan & \\
\hline
\end{tabular}

Gambar 7. Gap Analisis Sistem Informasi 
Gap analisis ini digunakan untuk menentukan tindakan yang diperlukan pada sistem informasi yang merupakan hasil perencanaan strategis sistem informasi terhadap sistem informasi yang sudah tersedia pada STMIK Cahaya Surya Kediri. Hasil gap analisis dapat dilihat pada Gambar 7.

Dari tabel gap analisis tersebut, terdapat tiga (3) kriteria tindakan yang harus dilakukan terhadap sistem informasi yang sudah ada maupun yang akan diajukan. Penjelasan dari kriteria tindakan tersebut adalah:

1. Kembangkan

Kriteria ini berarti bahwa sistem informasi yang ada perlu untuk dikembangkan fiturnya sehingga terpenuhi fungsi-fungsi yang diperlukan dari sistem informasi tersebut terhadap kebutuhan yang akan datang.

2. Tetap

Kriteria ini berarti bahwa sistem informasi yang sudah ada tetap dapat digunakan karena sudah sesuai dengan kebutuhan yang akan datang.

3. Baru

Kriteria ini berarti bahwa sistem informasi tersebut belum ada dan dibutuhkan untuk mendukung proses bisnis organisasi. Karena itu sistem informasi ini harus disiapkan untuk mendukung kebutuhan yang akan datang.

Implementasi dari perencanaan strategis sistem informasi akan membutuhkan waktu tertentu. Oleh karena itu, perlu dibuatkan perencanaan implementasi yang tertata dengan baik, sehingga hasil akhir sebuah perencanaan sistem informasi dapat terpenuhi secara menyeluruh.

Waktu implementasi yang dibutuhkan pada STMIK Cahaya Surya Kediri ini direncanakan dapat diselesaikan dalam waktu empat (4) tahun. Rekomendasi jadwal implementasi perencanaan strategis sistem informasi pada STMIK Cahaya Surya Kediri ditunjukkan pada Gambar 8.

\begin{tabular}{|c|c|c|c|c|c|c|c|c|c|c|c|c|}
\hline \multirow{2}{*}{ Nama Kegiatan } & \multicolumn{3}{|c|}{ Tahun Ke-1 } & \multicolumn{3}{|c|}{ Tahun Ke-2 } & \multicolumn{3}{|c|}{ Tahun Ke-3 } & \multicolumn{3}{|c|}{ Tahun Ke-4 } \\
\hline & Q1 & $Q 2$ & Q3 & Q1 & Q2 & $Q 3$ & Q1 & $Q 2$ & Q3 & Q1 & $Q 2$ & $Q 3$ \\
\hline \multicolumn{13}{|l|}{ Strategi Manajemen SI } \\
\hline \multicolumn{13}{|l|}{ Perubahan Struktur Organisasi } \\
\hline \multicolumn{13}{|c|}{ Pengembangan Kompetensi SDM SI/TI } \\
\hline \multicolumn{13}{|l|}{ Sosialisasi Kebijakan SI/TI } \\
\hline \multicolumn{13}{|c|}{ Perekrutan Staff SDM SI/TI Kompeten } \\
\hline \multicolumn{13}{|l|}{ Strategi SI } \\
\hline \multicolumn{13}{|l|}{ Pengembangan Website Utama } \\
\hline \multicolumn{13}{|l|}{ Pembuatan SI kategori Strategic } \\
\hline \multicolumn{13}{|c|}{ Pembuatan SI kategori Key Operational } \\
\hline \multicolumn{13}{|c|}{ Pembuatan SI kategori High Potential } \\
\hline Pembuatan SI kategori Support & & & & & & & & & & & & \\
\hline
\end{tabular}

Gambar 8. Rencana Implementasi

\section{KESIMPULAN}

Berdasarkan strategi bisnis SI, diperlukan visi misi SI/TI yang dapat selaras dengan visi, misi, serta tujuan dari STMIK Cahaya Surya Kediri.

Berdasarkan strategi manajemen SI/TI, diperlukan restrukturisasi organisasi (penambahan divisi baru yang khusus menangani hal yang berkaitan dengan SI/TI institusi), pengembangan kompentensi SDM SI/TI, dan kebijakan SI/TI agar keberadaan SI/TI pada STMIK Cahaya Surya Kediri tidak menjadi penghambat kegiatan bisnis kampus dan layanan SI/TI dapat terlaksana dengan baik.

Berdasarkan strategi SI, dibutuhkan sebanyak dua puluh satu (21) sistem informasi yang sudah dipetakan ke dalam McFarlan Strategic Grid untuk mendukung kegiatan bisnis berupa 
aktifitas utama dan aktifitas pendukung pada STMIK Cahaya Surya Kediri agar proses bisnis menjadi lebih efisien.

Berdasarkan GAP Analysis IS, dari dua puluh satu (21) sistem informasi yang diperlukan, sebanyak empat belas (14) sistem informasi harus dibuat baru, tiga (3) sistem informasi memerlukan pengembangan dari sistem yang sudah ada, dan empat (4) sistem informasi yang sudah tersedia pada STMIK Cahaya Surya Kediri.

Berdasarkan rencana implementasi, diperlukan waktu setidaknya empat (4) tahun supaya perencanaan strategis sistem informasi dapat diimplementasikan dengan baik.

\section{SARAN}

Saran untuk penelitian selanjutnya adalah perencanaan strategis sistem informasi dapat dilakukan dengan metodologi yang berbeda sehingga didapatkan hasil yang dapat menjadi perbandingan ataupun referensi; Sistem informasi yang diajukan dalam penelitian ini dapat dibuat hingga bentuk blueprint-nya pada penelitian selanjutnya.

\section{DAFTAR PUSTAKA}

[1] Rosyidi, R., 2012, Perencanaan Sistem Informasi Strategis STMIK AMIKOM Purwokerto, Tesis, Magister Teknik Informatika STMIK AMIKOM Yogyakarta, Yogyakarta.

[2] Licantik, 2013, Perencanaan Strategis Teknologi Informasi di Lingkungan Pemerintah Daerah Kabupaten Gunung Mas Provinsi Kalimantan Tengah. Jurnal Informatika dan Komputer, Teknomatika, Vol 5, No 2.

[3] Robbins, S. P., Coulter, M., 1999. Manajemen. Jilid 1. Alih Bahasa: Drs. T. Hermaya. PT. Prenhallindo, Jakarta.

[4] Ward, J., Peppard, J., 2002, Strategic Planning for Information System, Third Edition, John Willey \& Sons, England.

[5] O'Brien, J., 2003. Introduction to Information Systems. 11 ${ }^{\text {th }}$ Edition. McGraw Hill, Higher Education, New York.

[6] Callon, J. D., 1996, Competitive Advantage, Through Information Technology, McGraw-Hill, London.

[7] Porter, M. E., 1998, Competitive Strategy, The Free Press A Division of Macmillan, Inc., New York. 